\title{
The utility of variability in probability leaming'
}

DAVID M. MESSICK

UNIVERSITY OF CALIFORNIA, SANTA BARBARA

\begin{abstract}
Abstraet
An experiment is reported which investigates the validity of Siegel's concept of the utility of variability. Human Ss predicted which of two types of stimuli would occur on each of 240 trials. Half of the $40 \mathrm{Ss}$ had 2 responses ( 1 for each type of stimulus) while the other half had 10 (5 for each type). Within each of these groups, half the Ss saw 2 stimuli (1 of each type) and the other half saw 10 stimuli (5 of each type). Several predictions were made on the basis of Siegel's theory, but none were confirmed.
\end{abstract}

\section{Introduetion}

Many studies of human choice behavior in probabilitylearning experiments have clearly. demonstrated that humans do not always make the response which is most likely to be correct or to lead to a monetary payoff. Such data have caused some embarrassment to psychologists who like to conceive of human behavior as rational. A recent theory of human choice in probabilitylearning situations (Siegel, 1964) has attempted to account for this apparent nonrationality by postulating that human Ss attempt to maximize a utility function composed of two components-the utility for a correct choice and the utility for choice variability. With an appropriate definition of choice variability it becomes possible to show that it is not always rational, in terms of expected utility maximization, to select only the response which is most likely to be correct. This theory thus preserves the concept of rationality through the introduction of the notion of the utility of choice variability.

Convincing empirical validation of this notion, however, has not been forthcoming. Siegel (1964) reports a single experiment which deals directly with the utility of variability and finds that his experimental manipulation of increasing the cognitive and kinesthetic enrichment increases the average proportion of choice of the most likely response only slightly. The difference between his control and experimental groups is significant at the .06 level, using a one-tailed test.

The study reported here was designed to investigate further the applicability of the concept of the utility of variability to probability-learning situations. Siegel (1964) argues that increasing the number of possible responses which Ss can make has the effect of reducing the utility for variability, allowing $\mathrm{S}$ to respond more often with the most frequently rewarded choice. To the extent that this is true, permitting $S$ to make a variety of equivalent responses in a probability learning situation should increase the proportion of choices of the most frequently rewarded response. Furthermore, to the extent that stimulus variability decreases the utility of choice variability, as Siegel implies, then increasing stimulus variability should also increase the relative frequency of response with the most frequently rewarded response.

\section{Method}

The Ss were 40 undergraduates enrolled in the introductory psychology course at the University of California, Santa Barbara. The task presented to the Ss was a version of the standard probability-learning task. $S$ was instructed that he would be shown a series of slides which would be projected on a translucent screen from an adjacent room. He was told that the slides, 3 by 3 matrices containing 0 's and 1 's, would be of two types and that his task was to predict on each trial which type of slide would appear. To make his prediction, $\mathrm{S}$ had before him a panel containing 10 switches, numbered 0 through 9 . The response was made be depressing one of the switches. The response panel was connected to a read-out device which was visible to $\mathrm{E}$, who recorded S's choices, but not to S. For half of the Ss, each slide contained either no 1 's or nine 1 's. Thus for these Ss, only two different stimuli occurred. Their task was to predict whether the next slide would have 0 or 91 's. For the other half of the Ss, each slide could contain $0,1,2, \ldots$, or 91 's. This group saw 10 different types of slides. Their task was to predict whether the next slide would contain four or fewer 1's, or five or more 1's. For both groups, the task was to predict which of the two types of stimuli would occur. In the first group (2S), there were only 2 stimuli, while in the second group (10S), there were 10 stimuli, 5 of each type.

Each of these groups was further divided into two groups of $10 \mathrm{Ss}$ by allowing half of the Ss to make one of two prediction responses and by allowing the other half to make 1 of 10 responses. The Ss who. were permitted to make only two responses (2R) were instructed to press the switch labelled " 0 "' to predict that the next slide would contain 01 's (in group $2 S$ ) or to predict that the next slide would contain between 0 and 41 's (in Group 10S). A response of "g" represented a prediction of 91 's in the former group and a prediction of between 5 and 91 's in the latter.

The Ss who were permitted 10 responses (10R) were told to press any switch between 0 and 4 to make a prediction of a Type 1 stimulus (0 1's or $0-41$ 's) and to press any switch between 5 and 9 to predict a Type 2 stimulus (9 1's or 5-9 1's). Thus if S responded with switch " 2 " (Type 1 prediction) and the actual number of 1 's in the next slide was 4 (or $0,1,2$, or 3 ), then $S$ was correct.

The stimuli were arranged randomly in the carriage of a Kodak Carousel projector. Eighty slides were used for Group 2S and 80 others for Group 10S. In both groups, the proportion of Type 1 stimuli was .788 (63 of the 80 
TABLE I

Average proportions of Type 1 predictions in final block of 40 trials

\begin{tabular}{lccc} 
& & \multicolumn{2}{c}{ Number of stimuli } \\
\hline Number of & 2 & 2 & 10 \\
\cline { 2 - 4 } Responses & 10 & .788 & .710 \\
\hline
\end{tabular}

slides). Moreover, in both groups, the sequential order of the types of stimuli was identical. If, for example, the 28th stimulus in Group $2 \mathrm{~S}$ was Type 1 (i.e., contained 01 's) then the 28th stimulus in Group 10S was Type 1 (i.e., contained between 0 and 41 's). On each trial, $S$ made a prediction as to the type of stimulus which would occur. The next slide was then projected, and $\mathrm{S}$ observed whether he was correct or incorrect. The experiment lasted for 240 trials.

\section{Results}

To the degree that $\mathrm{S}$ have a utility for response variability, the Ss having 10 alternative responses will be able to vary their responses in predicting Type 1 or Type 2 stimuli. This, according to Siegel, will enable them to reduce the utility for variability which will lead them to predict the most frequent stimulus more frequently than Ss having only two responses. Furthermore, the $10 \mathrm{~S}$ group will experience more "cognitive enrichment" than the 2S group which should similarly lead to more frequent predictions of Type 1 stimuli.

In Table 1 the average proportions of Type 1 predictions in the final 40 trials are presented for the four experimental groups. The average proportion in the $2 \mathrm{~S}$ groups is almost identically equal to the proportion of Type 1 stimuli observed, thus replicating the probability-matching phenomenon found in other probability learning experiments. It is of interest that having 10 responses available with two stimuli did not increase the proportion of Type 1 predictions at all.

An analysis of variance of the proportions of Type 1 predictions in the final 40 trials was performed. As is suggested by the means in Table 1, only the number of stimuli prove to have a significant effect. The difference, however, is in the opposite direction from that expected from Siegel's concept of utility for variability. The proportion of Type 1 responses is significantly lower for the $10 \mathrm{~S}$ groups than for the $2 \mathrm{~S}$ groups.

If Ss have a utility for response variability, then they should prefer to vary the responses used to predict Type 1 or Type 2 stimuli when they are able. The 10R groups have this capability in that they can make any of five equivalent choices to predict either a Type 1 or a Type 2 stimulus. Thus to test this implication of Siegel's concept, the number of different alternatives chosen in the last 40 trials was determined for each $\mathrm{S}$. Of the $10 \mathrm{Ss}$ in the 10R-2S group, 7 used only 2 (1 for each type of stimulus) of the possible 10 responses available. None of the Ss in this group used all 10 responses. However, in the 10R-10S group, 8 of the $10 \mathrm{Ss}$ used 8 or more of the 10 possible responses. The difference between the groups is significant beyond the .01 level by the median test. These data tend to support the hypothesis that response variability is more of a function of stimulus variability than an innate utility for response variability.

A final implication which may be evaluated from this experiment is that the greater the response variability, the lower the utility for variability. It follows from Siegel's model that the lower the utility for response variability, the greater the proportion for choices of the most frequently rewarded response. Thus, those Ss who show greater response variability should also show a larger proportion of Type 1 choices according to the model.

In the 10R-2S group, exactly half of the Ss used only 2 of the 10 responses throughout the entire experiment. The average proportion of Type 1 choices for these $5 \mathrm{Ss}$ in the last 40 trials is .868 . The average proportion for those 5 Ss who used more than the minimal number of responses is .707 . This difference is significant beyond the .05 level, but again the difference is in the direction opposite that predicted by Siegel's model.

In the 10R-10S group, 7 of the Ss used all $10 \mathrm{re-}$ sponses at least once during the 240 trials. The average proportion of Type 1 choices for these Ss in the final block of 40 trials was .686 , compared to .797 for the $3 \mathrm{Ss}$ in this group who used fewer than 10 responses. While this difference is not significant $(p=.13)$ it is of interest since it is in the same direction as that in the 10R-2S group. These data suggest that the larger the number of different responses used by $\mathrm{S}$, the less frequently will $\mathrm{S}$ choose the responses most likely to be correct.

\section{Conclusions}

In summary, the data from this experiment cast considerable doubt on the validity of the concept of utility for choice variability. With both 2 and 10 stimuli, there is no difference in the proportion of Type 1 choices resulting from having 10 as opposed to 2 distinct responses. Increasing the number of stimuli from 2 to 10 , however, produces a significant decrease in the proportion of Type 1 choices. Furthermore, when it is possible for Ss to vary their responses (as in the 10R groups) and to choose the most rewarding alternative simultaneously, the degree to which Ss do vary their choices seems to depend less on a basic preference for response variability than on the variability of the stimuli. Finally, in opposition to Siegel's prediction, these data suggest that the more Ss vary their choices, the less frequently they choose the response most likely to be correct.

\section{Reference}

Siegel, S. Choice, strategy, and utility. New York: McGraw-Hill, 1964 .

\section{Note}

1. The research reported here was supported by General Research Grant No. 372 from the Academic Senate of the University of California, Santa Barbara. The assistance of Mr. Warren Thorngate in collecting and summarizing the data is gratefully acknowledged. 